\title{
Editorial
}

\section{Déjà vu: Might Future Eruptions of Hunga Tonga-Hunga Ha'apai Volcano be a Repeat of the Devastating Eruption of Santorini, Greece (1650 BC)?}

\author{
Timothy M. Kusky \\ Center for Global Tectonics, Three Gorges Research Center for Geo-Hazards, China University of Geosciences, Wuhan 430074, China \\ (iDTimothy M. Kusky: https://orcid.org/0000-0002-4553-620X
}

The remote Pacific islands nation of Tonga (about 170 islands, with a population of 105000 ), and surrounding countries, are suffering from the damage from one of the largest, most explosive volcanic eruptions in at least several decades, at least since the 1991 eruption of Pinatubo in the Philippines. The data is still coming in from the Jan. 15, 2022 eruption. Initial reports show (remarkably) few casualties, but the islands are still (as of this writing) inaccessible because of thick volcanic ash coverings, loss of communication networks, and damage to the main airport. Initial reports are optimistic, but the observations and data are sparse. Tonga needs help, immediately.

Tonga is located in the northern part of the Tonga-Kermadec subduction system, that extends for about $2550 \mathrm{~km}$ between New Zealand and Tonga. It has the deepest trench in the southern hemisphere, and the second deepest in the world. The convergence rate between the Pacific Plate on the east and the TongaKermadec arc to the west is about $15 \mathrm{~cm} /$ year (some estimates in the far north suggest it may be $24 \mathrm{~cm} /$ year), showing that this trench records the fastest plate velocities on Earth (e.g., van de Lagemaat et al., 2018), which certainly contributes to its long history of earthquakes, volcanic eruptions and tsunami. The back arc side of the Tonga-Kermadec arc is extensional, forming a complex back-arc basin system extending from the Lau Basin in the north, to the Taupo volcanic zone in New Zealand in the south (Fig. 1a, inset). The Hunga Tonga-Hunga Ha'apai volcano (Figs. 1a, 1b, 1c) is located in the southern part of the Tonga segment of the Tonga Kermadec arc (Plank et al., 2020; Cronin et al., 2017), and before 2014, consisted of two andesitic islands (Honga Tonga in the northeast and Hunga Ha'apai in the west; Figs. 1b, 1c)), and have had notable eruptions before this phase in 2014, 2009, 1988, 1937, and 1912 (Smithsonian Museum, Global Volcanism Program, 2022; Bryan et al., 1972). The largest part of the volcano is a giant submarine caldera, located to the SE of the islands (Fig. 2). Some information suggests that Hunga Tonga-Hunga Ha'apai has had catastrophic eruptions similar in scale to the 2022 eruption about 1000 , and 2000 years

*Corresponding author: tkusky@gmail.com

(C) China University of Geosciences (Wuhan) and Springer-Verlag GmbH Germany, Part of Springer Nature 2022

Manuscript received January 19, 2022.

Manuscript accepted January 23, 2022. ago, and the volcanic edifice was at times a huge volcano that periodically collapses during these catastrophic events (Cronin, 2022; Cronin et al., 2017).

The Hunga Tonga-Hunga Ha'apai volcano is located about $30 \mathrm{~km}$ from Tonga's island of Fonuafo'ou, and about $60 \mathrm{~km}$ from the largest island, Tongatapu, with the capital, Nuku'alofa (Figs. $1,2)$. The main eruption sequence started on Jan. 14, with a major ash and steam eruption, accompanied by a magnitude 5.8 earthquake at $5 \mathrm{~km}$ depth (Global Alert and Disaster Coordination System, GDACS), accompanying the volcanic plume that rapidly reached to more than $20 \mathrm{~km}$ in the atmosphere. The largest eruption so far was on Saturday, Jan. 15.

The blast on Jan. 15 (5:10 a.m. Jan. 15 GMT; 6:10 p.m. local time), after some days of major eruptions (Figs. 3, 4), started with a magnitude 4.5 earthquake, and a sonic explosion that was, remarkably, detected around the world, as the volcano possibly collapsed underwater and the seawater rushed in, causing a huge displacement of seawater. Residents of New Zealand, Australia, and Alaska reported sounds like "sonic booms" shortly after the time of the eruption (corresponding to the speed of sound travelling across the globe), while weather stations in Denver, and across the globe, recorded sudden pressure drops corresponding to passage of the pressure wave. Later, analysis of satellite data (Fig. 5) showed that the sonic blast was accompanied by the formation of atmospheric gravity waves that formed from vertical displacements of particles caused by the blast, from the sea surface to the ionosphere. This is the first such documentation of volcanically-induced gravity waves (Adam, 2022), and we speculate that their formation may have been aided by the sonic blast moving through the dense eruption column that had already reached to $20 \mathrm{~km}$ height, displacing the ash, and causing a ripple effect that propagated throughout the entire atmosphere, and rapidly spread around the globe. The volcanic plume and sonic blast were followed by a toxic cloud of sulfur dioxide, that was transported through parts of the Pacific by the remnants of a tropical cyclone.

The displaced seawater caused a Pacific-wide tsunami, initially thought to be about $1-1.3 \mathrm{~m}$ in height in Tonga, but was measured at up to $2.7 \mathrm{~m}$ in Japan. New reports from Tonga suggest that the tsunami may have at least locally reached 15 meters, making it one of the largest since the devastating Indian Ocean tsunami of 2004 (e.g., Kusky, 2008a). At least one person in Tonga was washed away in the tsunami, but the reports are not in from most

Kusky Timothy M., 2022. Déjà vu: Might Future Eruptions of Hunga Tonga-Hunga Ha'apai Volcano be a Repeat of the Devastating Eruption of Santorini, Greece (1650 BC)?. Journal of Earth Science, 33(2): 229-235. https://doi.org/10.1007/s12583-022-1624-2. http://en.earth-science.net 
of the islands at the time of this writing. The tsunami passed Hawai'i, caused damage in Santa Cruz CA, Peru, and other locations, while a few surfers in LA enjoyed the waves, surprisingly reaching $>1 \mathrm{~m}$ in places along the sunny California coast.

Most tsunami are caused by earthquakes that displace the sea-bed, forcing water out of the way, which forms huge fastmoving, large-amplitude tsunami. This one was different, and apparently made prediction and warnings to Pacific-wide coastal communities difficult. Preliminary interpretations (Yuen et al., unpublished data, based on observation from NASA) suggest that the energy was released so explosively it was more like a 10-megaton atomic explosion, not a typical earthquake or volcanic eruption. Thus, this tsunami was different, and caused more of a sloshing of the entire Pacific Ocean, and the atmospheric gravity waves (Fig. 5) are possibly the cause of the 10-20 cm tsunami reported in the Caribbean and Atlantic Oceans. Thus, we suggest that the Tonga tsunami was possibly caused by the rapid incursion of seawater into a collapsing molten magma-filled caldera, and from the preliminary observations, seems remarkably similar to one of the most devasting volcanic eruptions in recorded history; Thera, 3650 years ago, in what is now modern-day Santorini in Greece. The eruption of Thera caused vast destruction across the Mediterranean and the downfall of the Minoan civilization that inhabited Crete at that time. Let us look at what happened in the Mediterranean, 3650 years ago, to hopefully understand what we, as world citizens, can do to help the people of Tonga, today. The background and historical accounts of the eruption of Thera, below, are excerpted, adapted, and paraphrased from my book "Volcanoes: Eruptions and Other Volcanic Hazards" (Kusky, 2008b).
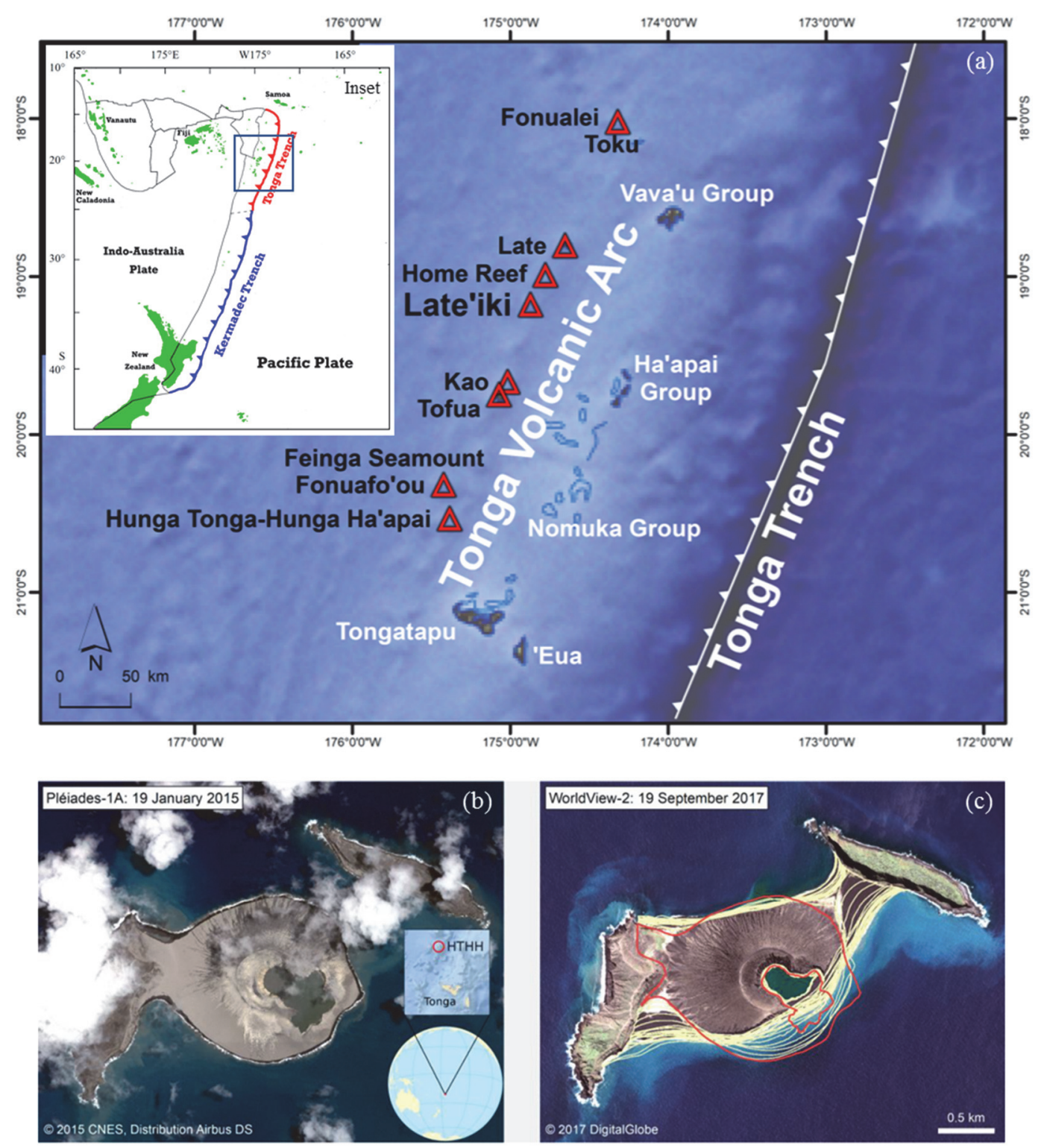

Figure 1. (a) Map of the Tonga volcanic arc (from Plank et al., 2020) showing the location of Hunga Tonga-Hunga Ha'apai volcano relative to the Tonga trench, the closest arc volcano to the main capital island of Tongatapu (lower center of the image). Inset map (box shows location of main figure) of the Tonga-Kermadec arc-trench system is from Wikimedia Creative Commons Attribution-Share Alike 4.0 International License. (b), (c) Airbus Pleiades-1A image of the newly formed cone that emerged from between the islands of Hunga Tonga (right) and Hunga Ha'apai (left) beginning on Dec. 19, 2014, and the new island as it appeared on Sept. 192017 (from Garvin et al., 2018). 


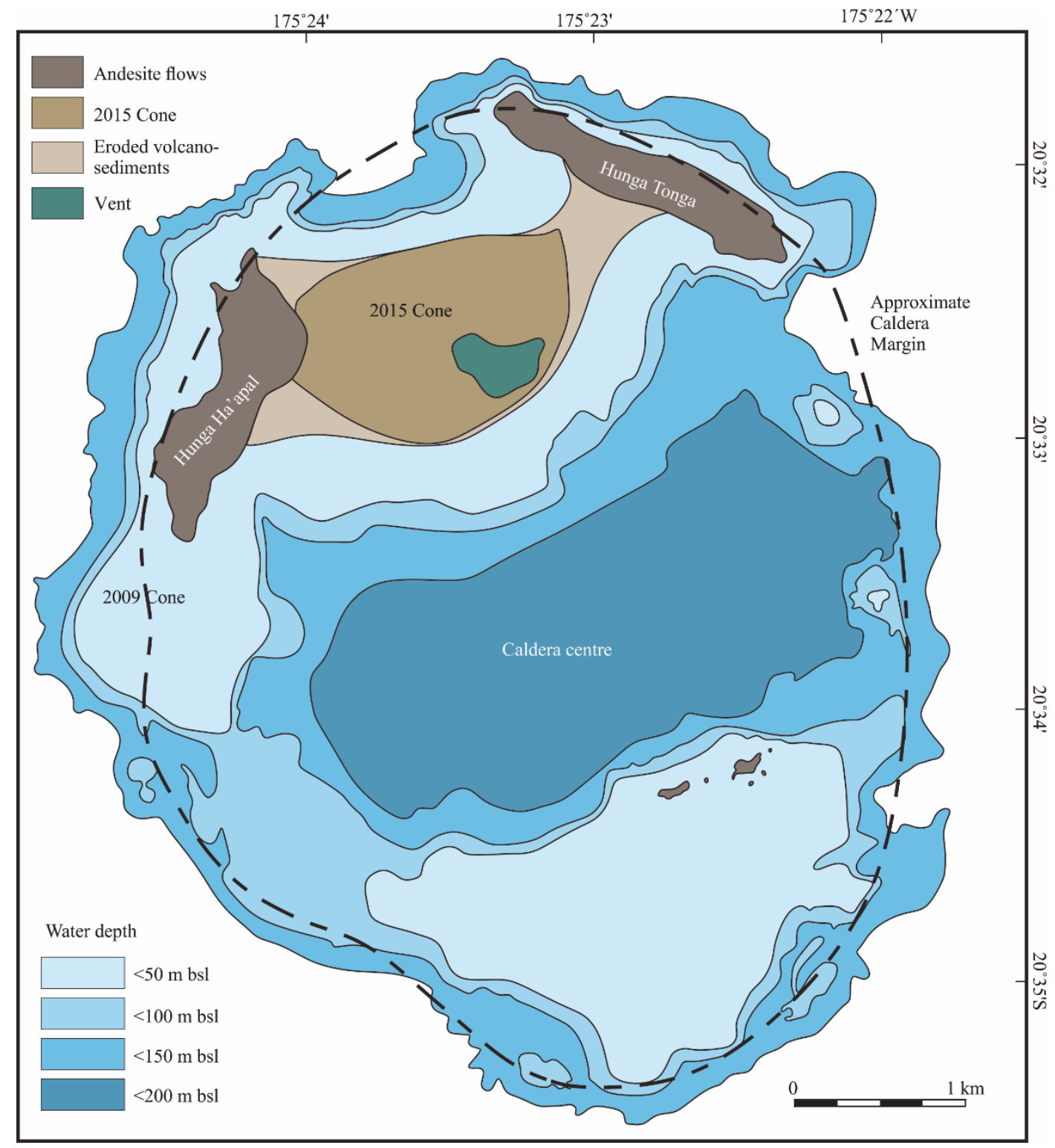

Figure 2. Map of the Hunga Tonga-Hunga Ha'apai islands and submarine caldera complex (underwater). The map is by Shane Cronin (University of Auckland, New Zealand), modifed after Cronin (2022). Compare with Fig. 1c for the emergent segments of the complex (in brown and green colors).

Santorini is a small, elliptically shaped archipelago (Fig. 6) approximately $16 \mathrm{~km}$ across, located about $110 \mathrm{~km}$ north of the island of Crete. These islands are dark and ominous in stark contrast to Greece's other white limestone islands, and they form ragged, 390-m peaks that seem to point up toward something that should be in the center of the ring-shaped archipelago, but is no longer there, ominously, like the Hunga Tonga and Hunga Ha'apai islands that fringe the central caldera (Figs. 1b, 1c), along with the new central island, that grew out of the sea from volcanic eruptions in 2014-2015 (Garvin et al., 2018; Cronin et al., 2017), and likely collapsed during the Jan. 15 eruption. The peaks surrounding the caldera at Santorini are pointing in and up toward the previous peak of a huge volcanic center, that collapsed to form a giant caldera complex that erupted in the late Bronze Age, approximately 3650 years ago, devastating much of the eastern Mediterranean. The largest island on the rim of the caldera is Thera and across two circular 275-300-m-deep calderas rest the opposing island of Therasia, once part of the same volcano. The volume of material between, and below, was blown away in the eruption, which currently seems to be the fate of at least parts of Hunga Tonga-Hunga Ha'apai.

In the center of the composite caldera complex are several smaller islands known as the Kameni Islands, which represent newer volcanic cones growing out of the old caldera, much like the new island between Hunga Tonga and Hunga Ha'apai that emerged in late 2014 and 2015 (Garvin et al., 2018; Cronin et al., 2017). Santorini and Thera are part of the Cyclades Islands that form part of the Hellenic volcanic arc that stretches from western Turkey through Greece, lying above a subduction zone in the Mediterranean along which part of the African plate is being pushed beneath Europe and Asia (Meng et al., 2021). Volcanoes in the Hellenic arc are widely spaced, and numerous earthquakes also characterize the region. The area was apparently densely populated, as remnants of Bronze Age and earlier Neolithic settlements and villages along the coastal Aegean are buried in ash from Thera. 


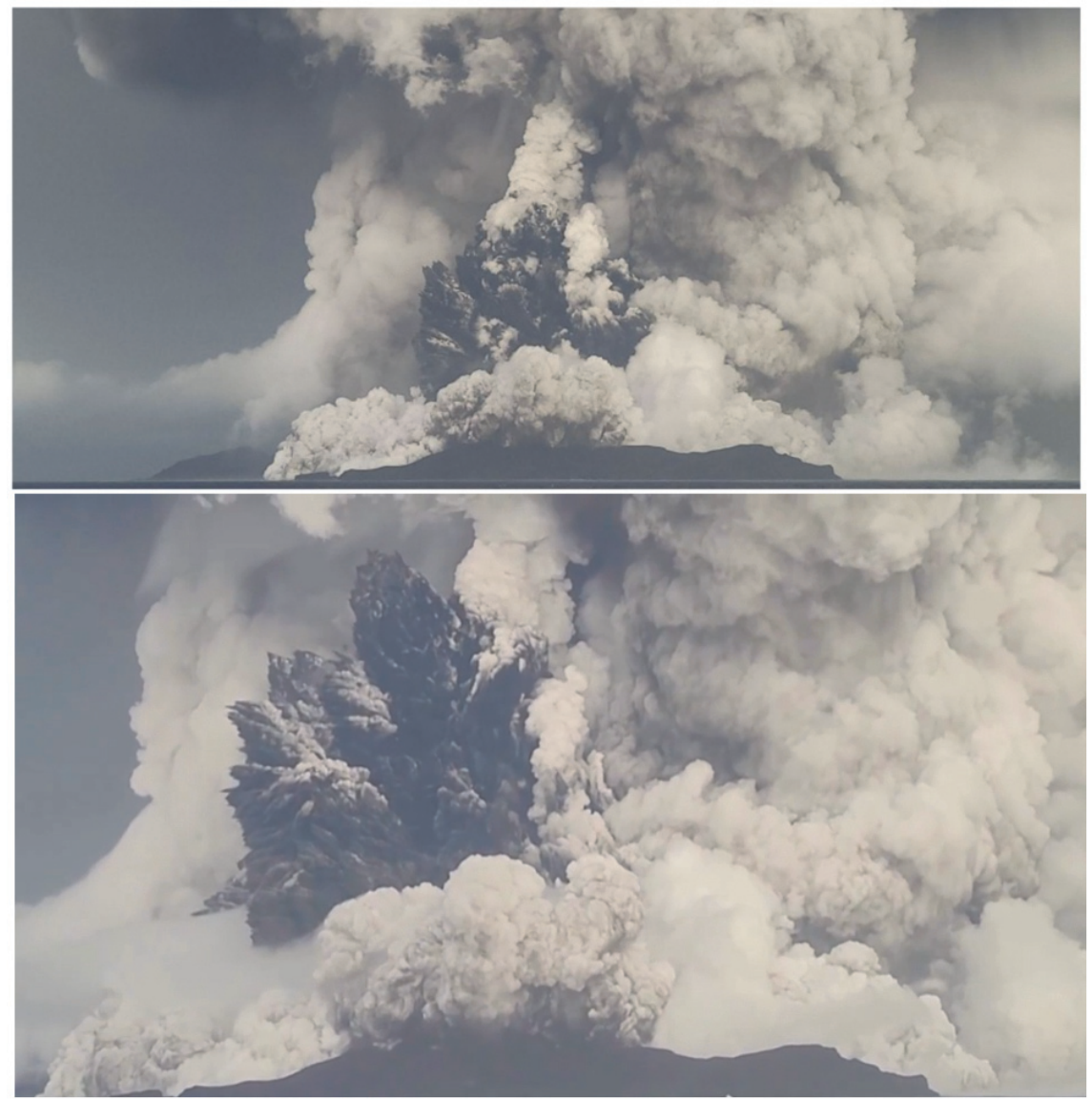

Figure 3. Two photos (taken looking eastward, from Tonga Geological Services) of the eruption at 5:27 p.m. Jan. 14, 2022, with a 5 km wide eruption column rising to $20 \mathrm{~km}$ height. Hunga Ha'apai in foreground, Hunga Tonga at far right. Note that these photos capture the eruptions the day before the major sonic blast eruption on Jan. 15, and may indicate the volcano was collapsing into the caldera.

Before the cataclysmic eruption, the Santorini Islands were one giant volcano known to the Greeks as Stronghyle, or the round one, and now referred to as Thera. We have no written firsthand accounts of the eruption of Thera, so the history has been established by geological mapping and examination of historical and archaeological records of devastation across the Mediterranean region. Volcanism on the island seems to have started 1-2 million years ago and continues to this day. It will not end until Africa finally collides with Eurasia, marking the final closure of the Tethyan seaway (Meng et al., 2021). Large eruptions are known to have occurred at $100000,80000,54000,37000$, and 16000 years ago; then, finally, 3650 years ago. The inside of Thera's caldera is marked by striking layers of black lava alternating with red and white ash layers, capped by a $60-\mathrm{m}-$ thick layer of pink to white ash and pumice that represents the deposits from the cataclysmic Bronze Age eruption. Ash from the eruption spread over the entire eastern Mediterranean and also on North Africa and across much of the Middle East. The most violent eruptions are thought to have occurred when the calderas collapsed and seawater rushed into the crater, forming a tremendous steam eruption and tsunami. This is what we suggest, based on very preliminary data, happened during the Jan. 15 Hunga Tonga-Hunga Ha'apai eruption. In the case of Thera, the tsunami moved quickly across the Mediterranean, devastating coastal communities in Crete, Greece, Turkey, North Africa, and the Levant. The tsunami was so powerful that it caused the
Nile to run backward for hundreds of kilometers. We are still unable to assess the damage to the remote islands of Tonga.

Detailed reconstructions of the eruption sequence of Thera reveal four main phases, that bear an uncanny resemblance to what we know about the recent events at Hunga Tonga-Hunga Ha'apai. The first was a massive eruption of ash and pumice that was ejected high into the atmosphere, collapsing back on Thera and covering nearby oceans with 3-4 m of pyroclastic deposits. This phase was probably a Plinian eruption column and its devastating effects on Thera made the island uninhabitable. Approximately 20 years passed before some settlers tried to reinhabit the island. This may be equivalent to the previous months of very active Plinian eruptions from Hunga TongaHunga Ha'apai. For Thera, next, huge fissures in the volcano began to open in the second phase, and seawater entered these and initiated large steam eruptions and mudflows, leaving deposits up to $20 \mathrm{~m}$ thick. The third phase was the most cataclysmic, as seawater began to enter deep into the magma chamber initiating huge blasts that were heard across southern Europe, northern Africa, and the Middle East. Sonic blasts, much like those accompanying the Jan. 15 Hunga Tonga-Hunga Ha'apai eruption, and pressure waves would have been felt for thousands of kilometers around. Huge amounts of ash and aerosols were ejected into the atmosphere, probably causing several days of virtual darkness over the eastern Mediterranean. The fourth phase of the eruption was marked by continued production of 
pyroclastic flows depositing many layers of ash, pumice, and other pyroclastic deposits around the island and nearby Aegean. Most estimates of the amount of material ejected during the eruption fall around 80 cubic $\mathrm{km}$, although some estimates are twice that amount. Ash layers from the eruption of Thera have been found in Egypt, Turkey, other Greek Islands, and across the Middle East.

Thera undoubtedly caused global atmospheric changes after ejecting so much material into the upper atmosphere. Data from Greenland ice cores indicate that a major volcanic eruption lowered Northern Hemisphere temperatures by ejecting aerosols and sulfuric acid droplets into the atmosphere in 1645 b.c.e. Additional evidence of an atmospheric cooling event caused by the eruption of Thera comes from tree ring data from ancient bristlecone pines in California, some of the oldest living plants on the planet. These trees, and other buried tree limbs from Ireland, indicate a pronounced cooling period from 1630 to 1620 b.c.e. European and Turkish tree ring data have shown cooling between 1637 and 1628 b.c.e. Chinese records show that at this time there were unusual acidic fogs (probably sulfuric acid) and cold summers, followed by a period of drought and famine. The eruption of Thera therefore caused not only the destruction of the Minoan civilization, but also changed atmospheric conditions globally, forming frosts in California and killing tea crops in China. Similar cooling of global temperatures occurred after other major historical eruptions, including Tambora (1815) and Krakatoa (1883), both in Indonesia, and Laki in Iceland (1783). Will Hunga Tonga-Hunga Ha'apai have a similar effect? Will this on-going eruption give us some time to try to correct global warming? Estimates of the volumes of gases, ash, and the possible effects of the atmospheric gravity waves on global atmospheric circulation are just beginning at the time of this writing, so we don't know yet. We also do not yet fully understand what effect the atmospheric gravity waves will have on global circulation patterns, or the effect on climate from this newly recognized phenomenon.

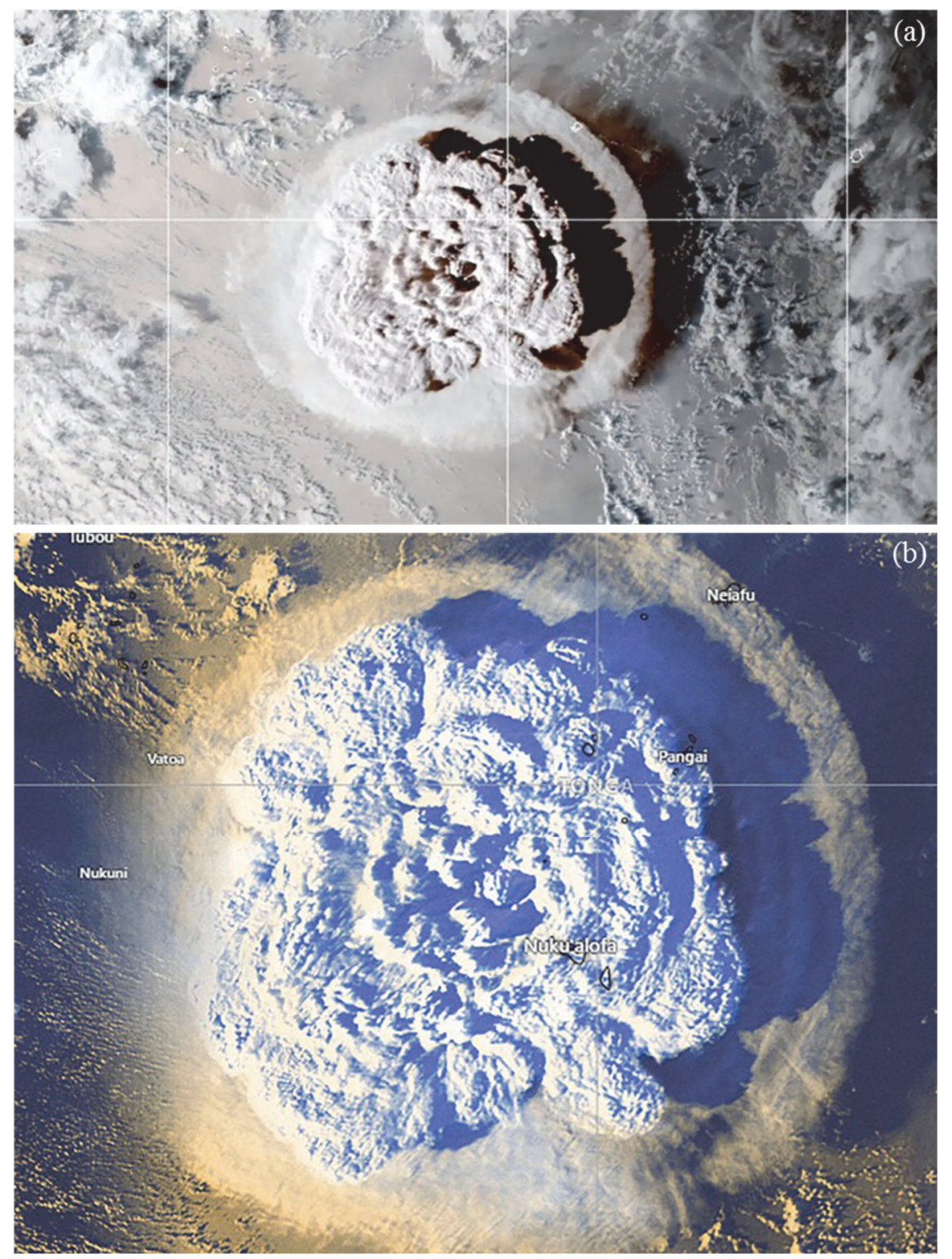

Figure 4. (a) GOES-West satellite image (US National Ocean and Atmospheric Administration) image of the sonic blast moving through the expanding eruption column taken at 5:10 a.m. Jan. 15 GMT (1:10 p.m., Beijing time, 6:10 p.m. Nuku'alofa time). (b) Enhanced image (from Tonga Meteorological Services), showing the location of the main island of Tonga, Tongatapu, with the capital city Nuku'alofa located near the center of the blast. 


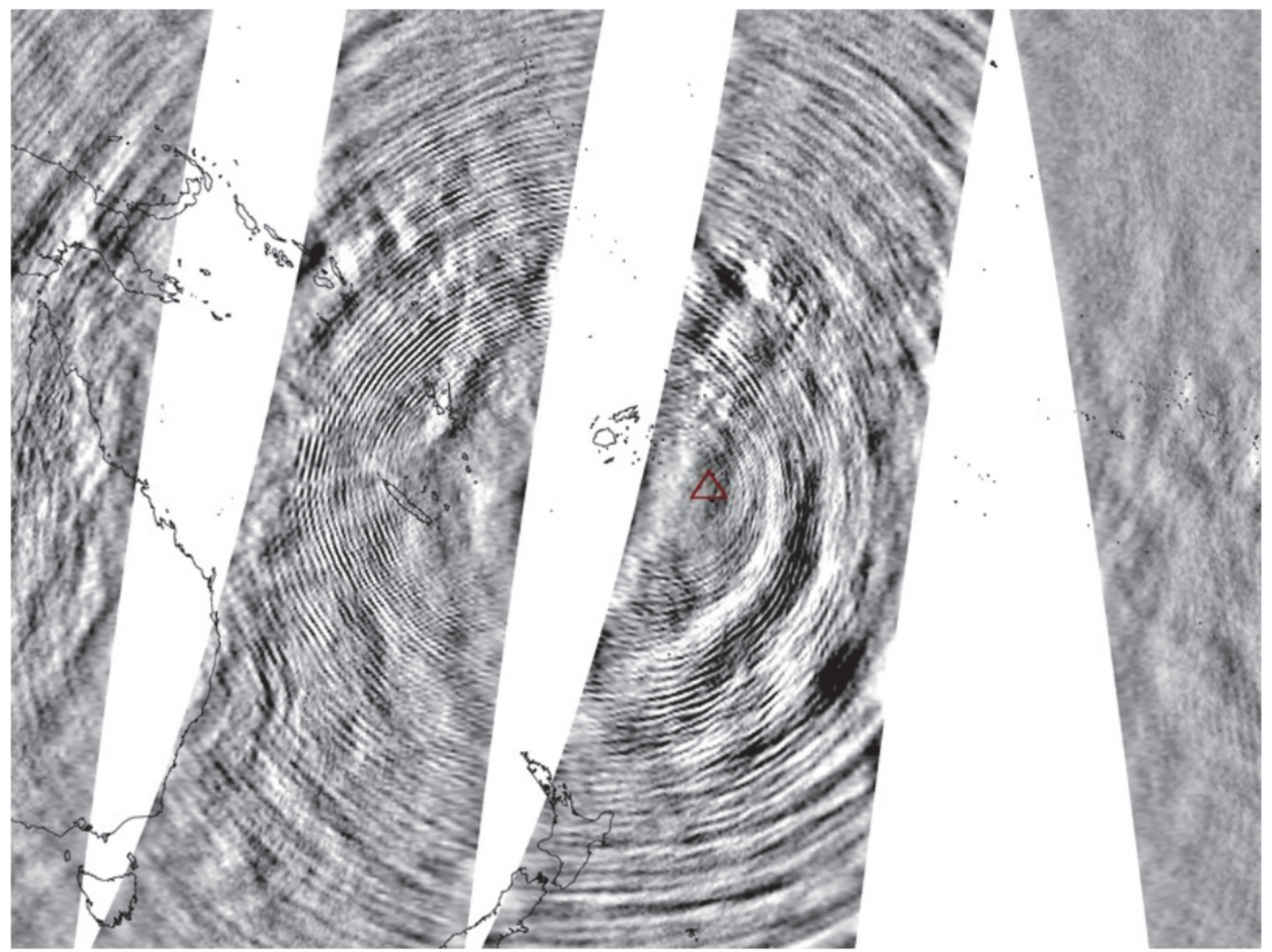

Figure 5. Atmospheric gravity waves (from AIRS Level-1 data by NASA DES DISC) extending $16000 \mathrm{~km}$ from the eruption, extending from the ocean surface to the ionosphere, and traveled around the globe several times. From Adam, 2022 (with credit to Lars Hoffmann, Jülich Supercomputing Centre).

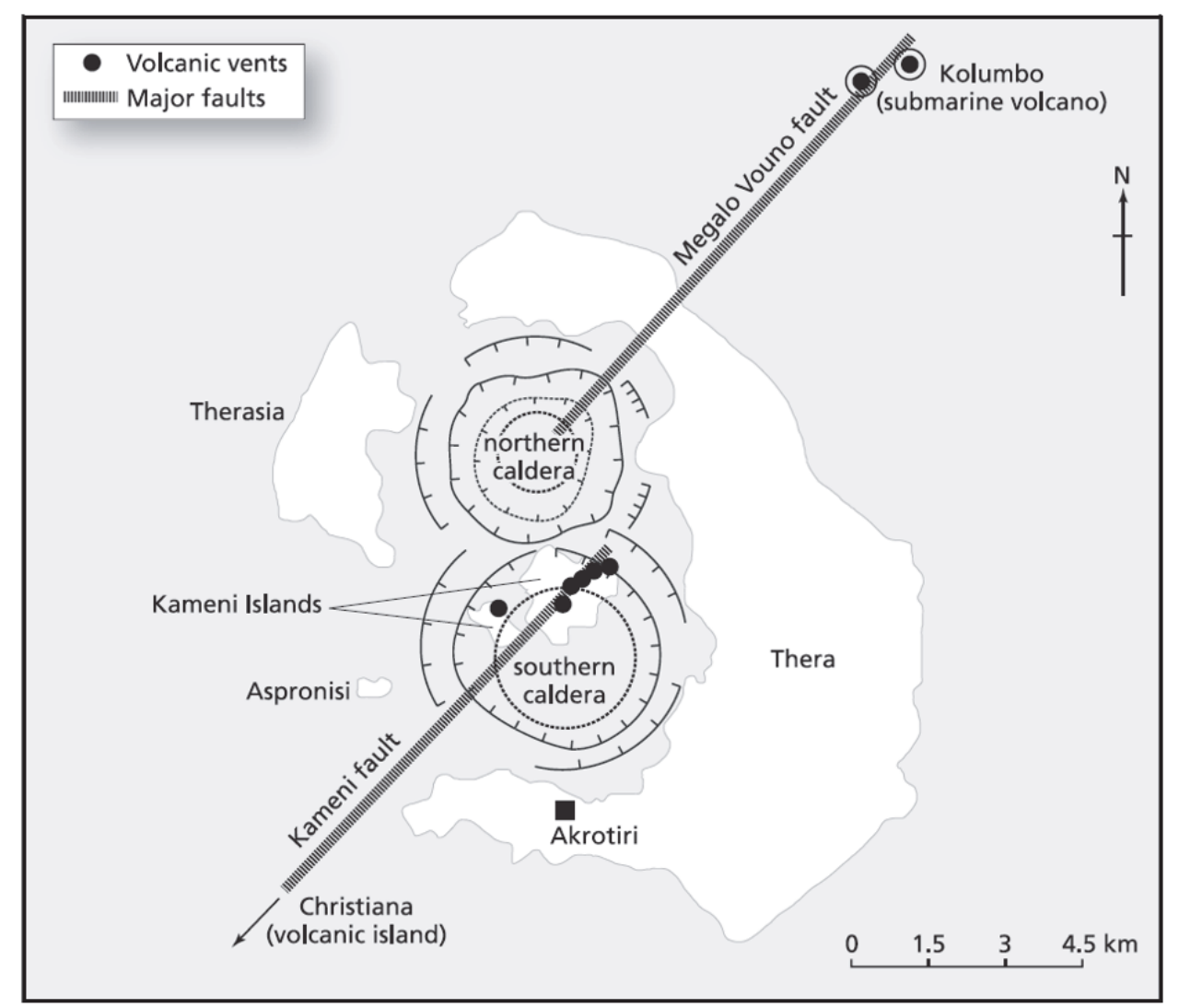

Figure 6. Map of the Santorini archipelago showing the two large calderas, surrounded by the islands of Thera and Therasia, much like Hunga Tonga-Hunga Ha'apai (compare with Fig. 1). Map modified slightly from Kusky, 2008b. 
The eruption of Thera coincided with the fall of the Minoan civilization, certainly in the Santorini archipelago, but also on Crete and throughout the eastern Mediterranean. The cause of the collapse of the Minoan society was probably multifold, including earthquakes that preceded the eruption, ashfalls, and the 9-m tsunami waves that swept the eastern Mediterranean from the eruption. Since the Minoans were sea merchants, the tsunami would have devastated their fleet, harbor facilities, and coastal towns, causing such widespread destruction that the entire structure of their society fell apart. Vessels at sea would have been battered by the atmospheric pressure waves, covered in ash and pumice, and stranded in floating pumice far from ports. Crops were covered with ash, and palaces and homes were destroyed by earthquakes. The ash was acidic, the same as from Hunga Tonga-Hunga Ha'apai, so crops would have been ruined for years, leading to widespread famine and disease. People sought relief by leaving Crete, the homeland of the Minoan culture. Many of the survivors are thought to have migrated to Greece and North Africa, including the Nile Delta region, Tunisia, and the Levant, where the fleeing Minoans became known as the Philistines.

This lesson from history should not be forgotten. The eruptions from Hunga Tonga-Hunga Ha'apai are not over, and could potentially be even worse in the coming days, weeks, and months. The question is, what can we do to help the people of Tonga, now, and for the future, so their culture does not have the same fate as the Minoans. What can we learn from this eruption, in terms of understanding Earth's most powerful forces, and the interaction of plate tectonics with climate, sustainability at local and global scales? It is time to act.

Specifically, Tonga needs international aid to ensure that their drinking water supply is safe, after contamination from the acidic ash. This is difficult because the population is widely dispersed across many islands. Food will be needed if the existing agricultural harvests have been destroyed and the fields acidified. On a longer scale, the international community can help Tongans better understand, predict, and mitigate geological hazards, and how to inform the communities what to do when more earthquakes, eruptions, or tsunami occur. On an international scale the scientific community can learn from this, in that we need a new class of tsunami models for this type of eruption, as the existing models seem inadequate to properly model this complex system, and give residents of any ocean basin with similar arc-related tsunami risks accurate information on evacuations or emergency measures. Finally, with the exceptional monitoring of this catastrophic event, the scientific community has a wealth of new data on atmospheric gravity waves caused by massive eruptions, and need to model potential effects on climate, and unexpected types of tsunami generated by the atmospheric pressure/gravity waves, and with better monitoring stations, of geologically well-mapped and studied volcanoes, seismologists might be better able to predict when such catastrophic eruptions may occur. We must better understand the relationships between tectonic processes on the planet, hazards to the places people live, and the interaction between deep Earth processes, catastrophic events, their influence on the atmosphere, and how to make a more livable sustainable planet.

\section{ACKNOWLEDGMENTS}

Data for this editorial were collected by the Tonga Geohazards team based in the Three Gorges Research Center for GeoHazards, Center for Global Tectonics, China University of Geosciences (Wuhan). Tonga Hazards Team: Timothy M. Kusky, Louisa Meyers Pale, Susana Unaloto Ki He Vahanoa Takau, Meletonga Kaituu, Jiannan Meng, Reda Amer. We thank Walter Mooney and Dave Yuen for insightful discussions. The final publication is available at Springer via https://doi.org/10.1007/s12583022-1624-2.

\section{REFERENCES CITED}

Adam, D., 2022. Tonga Volcano Eruption Created Puzzling Ripples in Earth's Atmosphere, News: Jan 18, 2022. Nature. https://www.nature.com/articles/d41586-022-00127-1

Bryan, W. B., Stice, G. D., Ewart, A., 1972. Geology, Petrography, and Geochemistry of the Volcanic Islands of Tonga. Journal of Geophysical Research Atmospheres, 77(8): 1566-1585. https://doi.org/10.1029/jb077i008p01566

Cronin, S., 2022. Why the Volcanic Eruption in Tonga was so Violent, and What to Expect Next, The Conversation, Jan. 15, 2022. https://theconversation.com/why-the-volcanic-eruption-in-tonga-was-so-violent-andwhat-to-expect-next-175035

Cronin, S., Brenna, M., Smith, I., et al., 2017. New Volcanic Island Unveils Explosive Past. Eos. https://doi.org/10.1029/2017eo076589

Garvin, J. B., Slayback, D. A., Ferrini, V., et al., 2018. Monitoring and Modeling the Rapid Evolution of Earth's Newest Volcanic Island: Hunga Tonga Hunga Ha'apai (Tonga) Using High Spatial Resolution Satellite Observations. Geophysical Research Letters, 45(8): 3445-3452. https://doi.org/10.1002/2017g1076621

Kusky, T. M., 2008a. Tsunami: Giant Waves from the Sea, The Hazardous Earth, Facts on File, New York. 133

Kusky, T. M., 2008b. Volcanoes: Eruptions and Other Volcanic Hazards, The Hazardous Earth, Facts on File, New York. 177

Meng, J. N., Sinoplu, O., Zhou, Z. P., et al., 2021. Greece and Turkey Shaken by African Tectonic Retreat. Scientific Reports, 11: 6486. https://doi.org/10.1038/s41598-021-86063-y

Plank, S., Marchese, F., Genzano, N., et al., 2020. The Short Life of the Volcanic Island New Late'iki (Tonga) Analyzed by Multi-Sensor Remote Sensing Data. Scientific Reports, 10: 22293. https://doi.org/10.1038/s41598-020-79261-7

Smithsonian Museum, Global Volcanism Program, 2022. Hunga TongaHunga Ha'apai. [2022-01-23]. https://volcano.si.edu/volcano.cfm?vn=243040

van de Lagemaat, S. H. A., van Hinsbergen, D. J. J., Boschman, L. M., et al., 2018. Southwest Pacific Absolute Plate Kinematic Reconstruction Reveals Major Cenozoic Tonga-Kermadec Slab Dragging. Tectonics, 37(8): 2647-2674. https://doi.org/10.1029/2017tc004901 